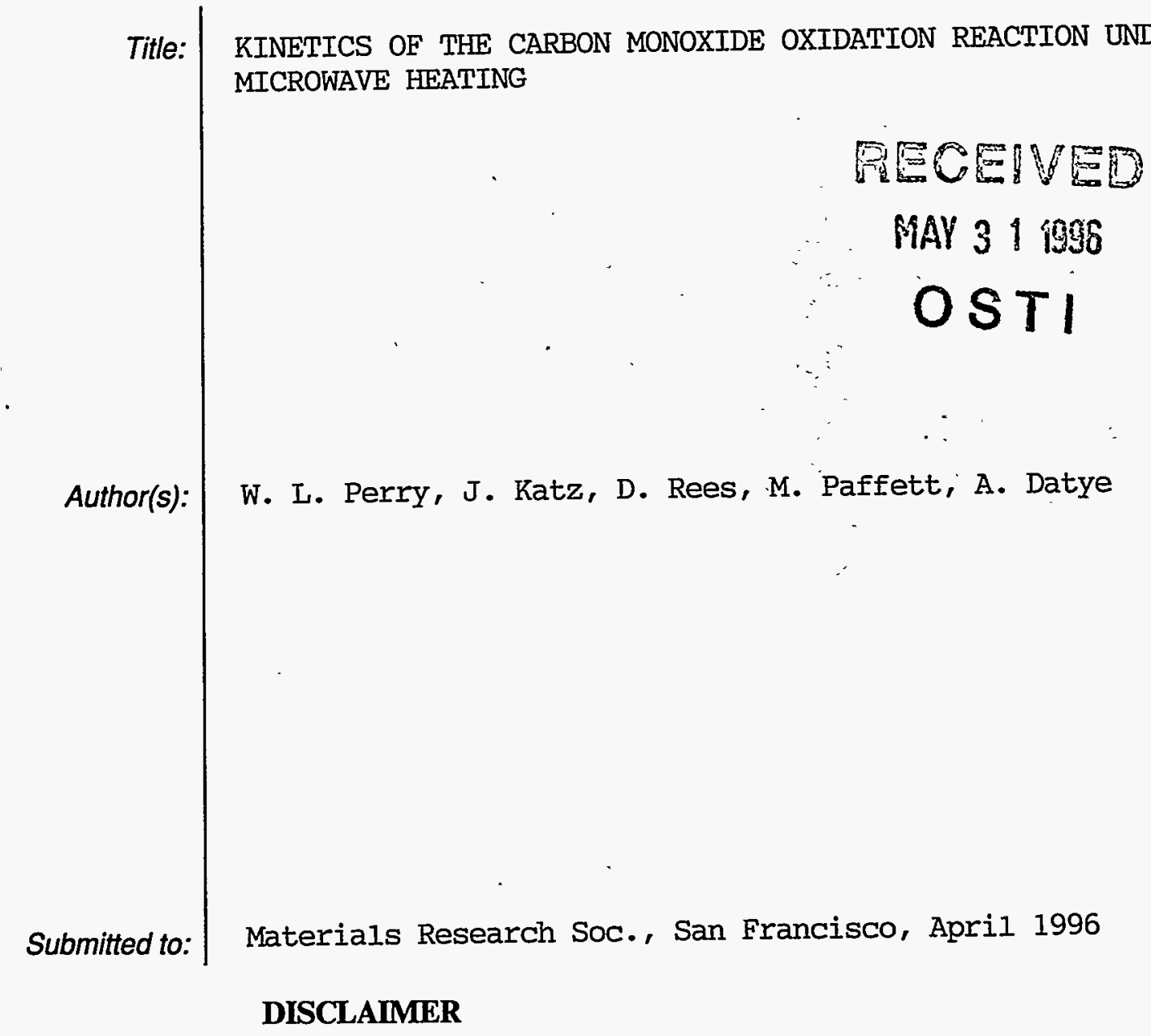

This report was prepared as an account of work sponsored by an agency of the United States Government. Neither the United States Government nor any agency thereof, nor any of their employees, makes any warranty, express or implied, or assumes any legal liability or responsibility for the accuracy, completeness, or usefulness of any information, apparatus, product, or process disclosed, or represents that its use would not infringe privately owned rights. Reference herein to any specific commercial product, process, or service by trade name, trademark, manufacturer, or otherwise does not necessarily constitute or imply its endorsement, recommendation, or favoring by the United States Government or any agency thereof. The views and opinions of authors expressed herein do not necessarily state or reflect those of the United States Government or any agency thereof.
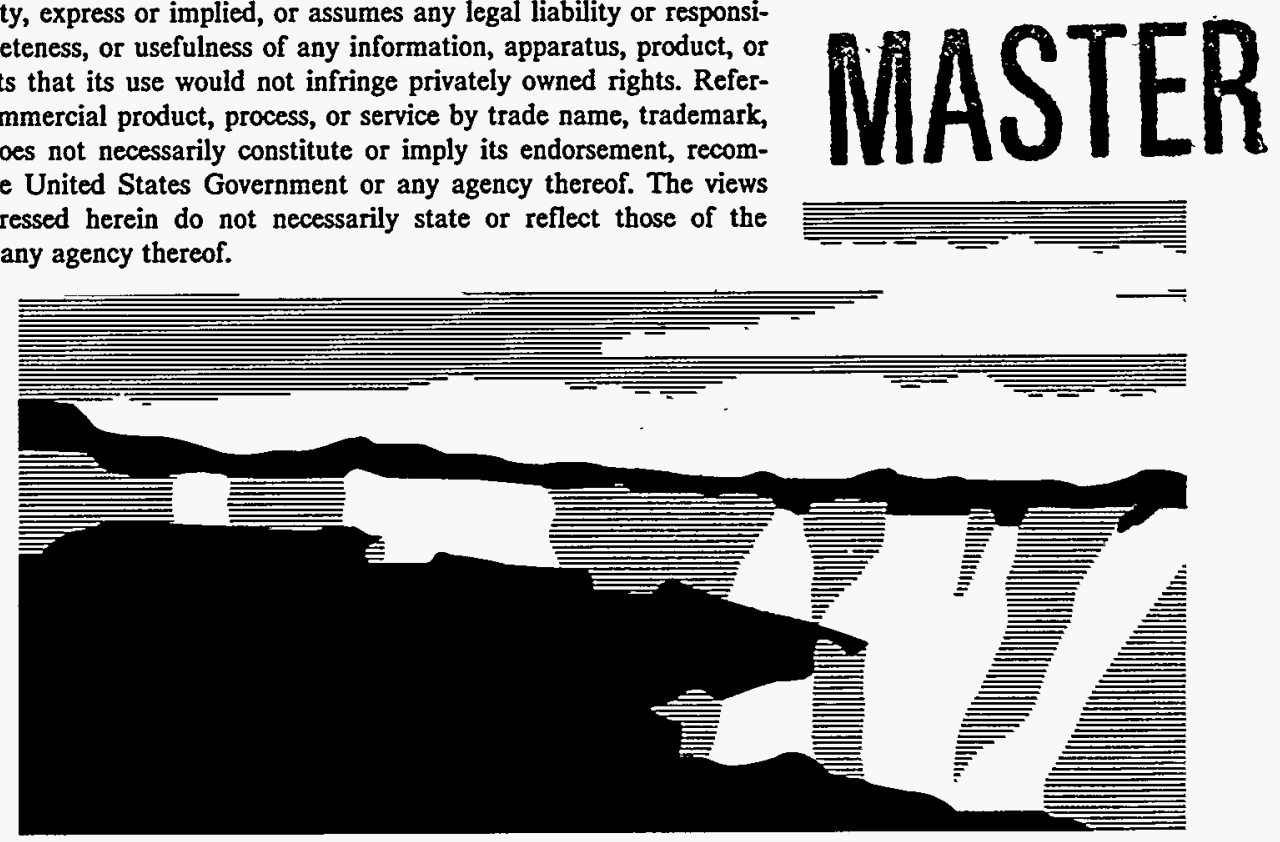

Los Alamos National Laboratory, an affirmative action/equal opportunity employer, is operated by the University of California for the U.S. Department of Energy under contract W-7405-ENG-36. By acceptance of this article, the publisher recognizes that the U.S. Government retains a nonexclusive, royalty-free license to publish or reproduce the published form of this contribution, or to allow others to do so, for U.S. Government purposes. The Los Alamos National Laboratory requests that the publisher identify this article as work performed under the auspices of the U.S. Department of Energy. 


\title{
Kinetics of the Carbon Monoxide Oxidation Reaction Under Microwave Heating
}

W. Lee Perry, Joel D. Katz, Daniel Rees, Mark T. Paffett

Los Alamos National Laboratory, Los Alamos, NM 87545

Abhaya Datye, University of New Mexico, Albuquerque, NM 87131

\begin{abstract}
$915 \mathrm{MHz}$ microwave heating has been used to drive the $\mathrm{CO}$ oxidation reaction over $\mathrm{Pd} / \mathrm{Al}_{2} \mathrm{O}_{3}$ with out significantly affecting the reaction kinetics. As compared to an identical conventionally heated system, the activation energy, pre-exponential factor, and reaction order with respect to $\mathrm{CO}$ were unchanged. Temperature was measured using a thermocouple extrapolation technique. Microwave-induced thermal gradients were found to play a significant role in kinetic observations.
\end{abstract}

\section{Introduction}

Microwave energy is an alternative to conventional heating in catalytic processes and has proved successful in driving the $\mathrm{CO}$ oxidation reaction over $\mathrm{Pd}$ and $\mathrm{Pt}$ on $\gamma-\mathrm{Al}_{2} \mathrm{O}_{3}$ without significantly affecting the reaction kinetics. There are many ways the microwave might interact with the catalyst to have an effect on chemical kinetics in this system: 1) space charge effects around the supported metal particles such that an induced surface charge has significant effect on the dipolar CO molecule either on/near the surface;. 2) differential heating of the metal versus the ceramic support; 3 ) the oxidation of the polar $\mathrm{CO}$ molecule could be affected both in the gas phase and near the catalyst surface by the electric field. If any of these effects were important, a significant alteration in the kinetics would be observed with respect to conventional heating.

In most of the literature reviewed $[1,2,3,4]$, beneficial effects of microwave heating were shown. However, little has been done to understand the effect of microwaves on the underlying kinetic and mechanistic process due to the difficulties experienced in measuring temperature and the non-isothermal nature of a microwave heated packed-bed. Because of the temperature gradients and lack of temperature data, it is difficult to ascertain the root cause of the beneficial effects. In the research presented, we have taken steps to determine the temperature and temperature gradients so that an accurate comparison of chemical kinetics during microwave and conventional heating can be made.

\section{Experimental}

In this paper we will compare the kinetics of the $\mathrm{CO}$ oxidation reaction over $\mathrm{Pt}$ and $\mathrm{Pd} / \gamma-\mathrm{Al}_{2} \mathrm{O}_{3}$ as observed in a specially constructed microwave heated differential [5] reactor. These kinetics ware compared to a conventionally heated reactor. To eliminate the effects of temperature gradients, a differential mass of active supported catalyst was sandwiched between two masses of inactive support inside a quartz tube, which was radially insulated with microwave transparent sapphire wool. The geometry located the active material on the maxima of the temperature profile, and the short length of the active material approximated an isothermal bed. A schematic of a typical experimental reactor is shown in Fig. 1. 


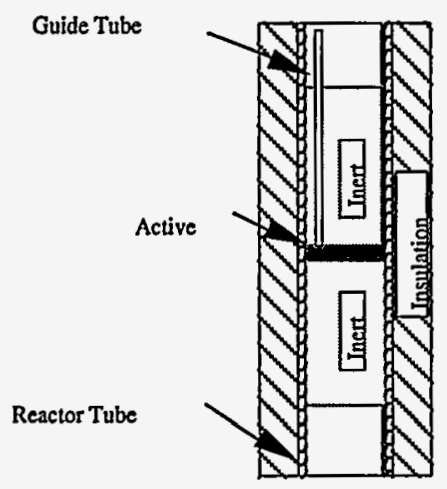

Figure 1. Schematic of reactor

configuration used in both the

microwave and conventional

experiments. "Differential" active

catalyst zonewas axially thin to

minimize thermal gradients, and inert

material was also added to minimize

gradients. Insulation was provided to

minimize radial gradients.

We chose the $\mathrm{CO}$ oxidation reaction over a supported metal catalyst because the reaction kinetics are well known, and because of the diverse dielectric properties of the various elements in the system: $\mathrm{CO}$ is a polar molecule, $\mathrm{O}_{2}$ and $\mathrm{CO}_{2}$ are non-polar, $\mathrm{Al}_{2} \mathrm{O}_{3}$ is a dielectric, and $\mathrm{Pt}$ and $\mathrm{Pd}$ are conductors. The literature $[6,7]$ has revealed the conventionally-heated reaction kinetic and mechanistic details, with the desorption of $\mathrm{CO}$ being the rate limiting step

The thermal reactor system was heated by a digitally controlled 1" tube furnace. The microwave reactor was heated by a magnetron based system operated on a continuous basis at $915 \mathrm{MHz}$. The power to the experiment was $850 \mathrm{~W}$ to $1000 \mathrm{~W}$ and was delivered to a resonant applicator via rectangular waveguide in the $\mathrm{TE}_{010}$ mode. The reactor tube was inserted through the rectangular resonant applicator parallel to the direction of the electric field. Product analysis was performed using gas chromatography . Reactant ratios were fixed by mass flow controllers, and the pressure was regulated by a bypass valve and monitored with a capacitance manometer.

The catalyst used for the final experiments was $5 \%$ (by weight) Palladium supported on $\gamma-\mathrm{Al}_{2} \mathrm{O}_{3}$. Preliminary experiments used $1 \% \mathrm{Pt} / \gamma-\mathrm{Al}_{2} \mathrm{O}_{3}$. To determine the activation energy, $E_{a}$, and the pre-exponential, $A$, factor in the Arrhenius expression temperature versus reaction rates were recorded. The flow rate for $\mathrm{CO}$ was $2 \mathrm{cc} / \mathrm{s}$ and $1 \mathrm{cc} / \mathrm{s}$ for $\mathrm{O}_{2}$, and the reactor pressure was fixed at 1000 Torr. The dependency on $\mathrm{CO}$ partial pressure was found by using an excess of oxygen and the $\mathrm{CO}$ partial pressure ranged from 35 - 95 Torr. The reactor pressure was held at 1000 Torr and the temperature was $135 \mathrm{C}$ for these experiments.

Temperature was measured in the microwave system by inserting a thermocouple into the bed after the microwave power was turned off. For the final experiments, the thermocouple was inserted through a "guide tube" (see Figure 1) until it came to rest in the hottest (active) part of the bed. The temperature decay curve was recorded on a $x-y$ recorder. The temperature versus time curve was linearized and coordinates were entered into a curvefitting routine. The routine provided an expression in the form $y=m x+b$ where $b$ was the initial temperature. The thermal mass of the thermocouple was not insignificant with respect to the mass of the bed and a corrective procedure was employed: The digitally controlled tube furnace was allowed to reach a known equilibrium temperature, furnace power was terminated, the furnace was opened, the thermocouple was inserted and the recorder was started. Several data points were recorded and a best fit line expression was then used to correct the temperature measurements.

\section{Results and Discussion}

Apparent kinetics. Early experiments were performed using an integral-type reactor [5]. A schematic of this reactor is shown in Figure 2 along with the comparative Arrhenius plot. The experiment used 2 grams of $1 \% \mathrm{Pt}_{\mathrm{Al}} \mathrm{O}_{3}$. The thermocouple extrapolation technique was employed and the probe was inserted such that it was in contact with the 
packed bed as shown in Fig 2. The microwave-heated packed bed was shown by thermal imaging in Figure 3 to be very non-isothermal. The non-isothermal nature of this packed bed precluded accurate temperature measurement and resulted in the apparent rate enhancement, activation energy and pre-exponential .

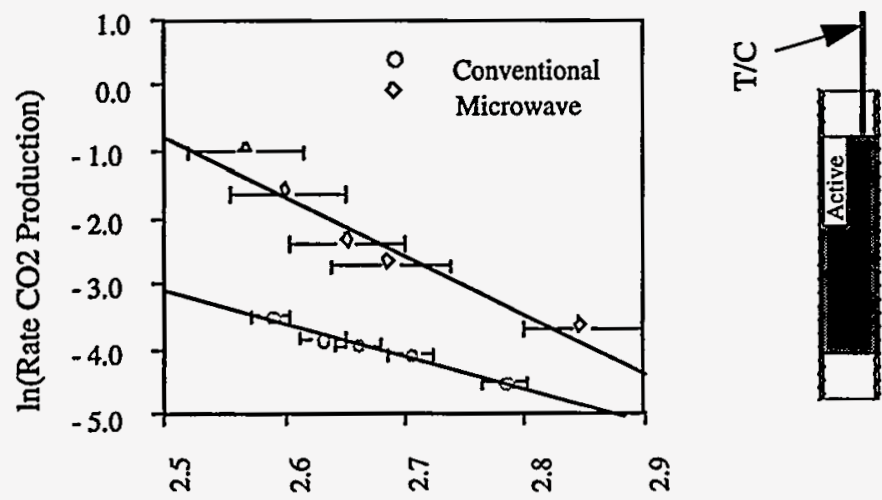

Figure 2. Comparative Arrhenius plot and Schematic of an integraltype packed-bed reactor. Error bars reflect maximum possible error.

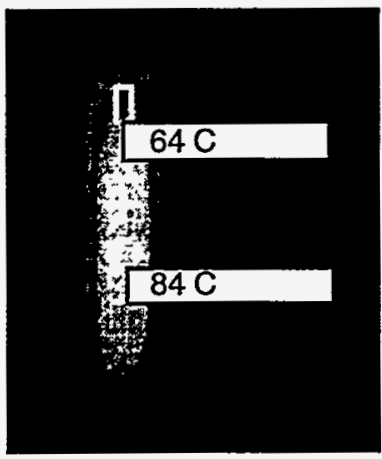

Figure 3. Thermal (infrared) image of microwave heated packed bed. Temperatures shown are the average temperatures of the areas outlined by the boxes.

A subsequent experimental design used $\alpha-\mathrm{Al}_{2} \mathrm{O}_{3}$ for the inert insulating material and $\gamma-\mathrm{Al}_{2} \mathrm{O}_{3}$ was used to support the active metal (see Fig. 1). Figure 4 shows a comparative Arrhenius plot and the associated thermal profile obtained from this differential configuration. The plot clearly shows an apparent rate enhancement. The probe was inserted into the active portion of the bed as shown in Figure 1. A qualitative experiment was performed, and $\gamma-\mathrm{Al}_{2} \mathrm{O}_{3}$ was observed to absorb microwave energy more efficiently than $\alpha-\mathrm{Al}_{2} \mathrm{O}_{3}$. Thus, the true reaction temperature was greater than the average, observable temperature as shown in Figure 4.

The true reaction temperature of the $\gamma-\mathrm{Al}_{2} \mathrm{O}_{3}$ was not observable with our technique for two reasons: 1 ) the mass of the active portion of the bed was much less than the inactive portion and the thermocouple will primarily "see" the inactive (cooler) mass; 2 ) the time required for the isolated $\gamma-\mathrm{Al}_{2} \mathrm{O}_{3}$ particles to cool to the temperature of the $\alpha-\mathrm{Al}_{2} \mathrm{O}_{3}$ was much less than the time required to insert the thermocouple. This time for cooling can be estimated rigorously by performing a transient heat conduction analysis. Because of the rapid cooling and low mass fraction, the reaction was occurring at a hotter temperature than was observed by the thermocouple and yielded the apparent results shown in Figure 4. 

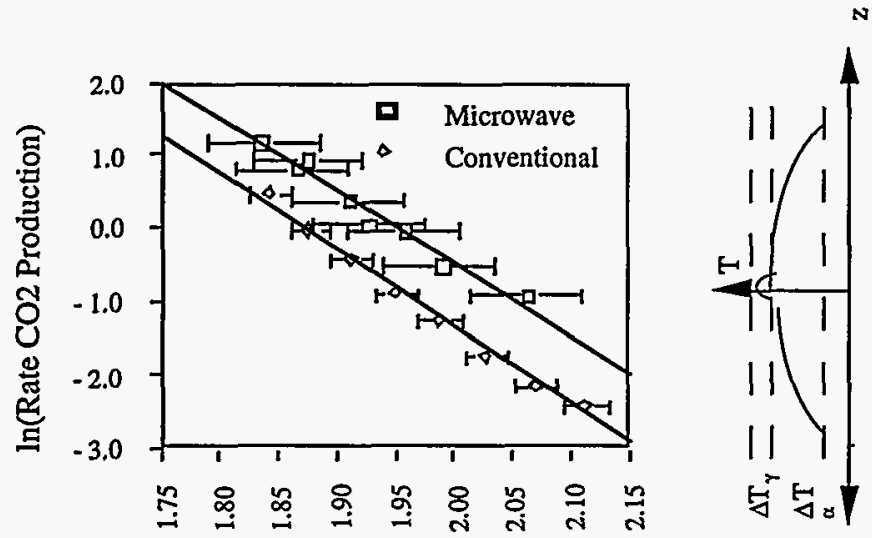

Figure 4. Result for differential type reactor where active catalyist was supportedon $\gamma$-alumina and insulating alumina was $\alpha$-type. This material mismatch gave rise to the qualitative temperature profile shown here. The rise at $\mathrm{z}=0$ results from more efficient absorption of microwave energy by the $\gamma$ alumina. Error bars reflect maximum error.

$1000 / \mathrm{T}(\mathrm{K})$

This experiment illustrates the difficulty in observing the proper temperature when one material absorbs more efficiently than another. The situation is analogous to the case where the supported metal particles absorb energy preferentially to the support. The metal particle temperature would not be observable due to the observability discussed above, and a discrepancy similar to that shown in figure 8 would result if preferential absorption were occurring.

True kinetics. A comparative Arrhenius plot is shown in Figure 5 for $\mathrm{CO}$ reaction over $\mathrm{Pd} / \gamma-\mathrm{Al}_{2} \mathrm{O}_{3}$. The reaction rates were nearly identical within experimental error. The slightly higher rate observed in the microwave reactor resulted from thermal gradients which cannot be eliminated and the reaction surface was always hotter than the average temperature observable using a thermocouple.

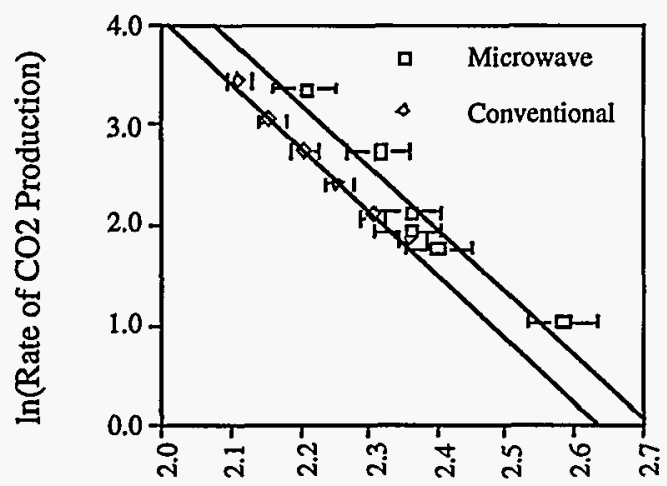

Figure 5. Plot shows comparison of data obtained in the microwave-heated reactor vs. the conventionally heated reactor. The slope of both lines is nearly identical, yeilding an activation energy of approximately $13 \mathrm{kcal} / \mathrm{mol}$. The proximity of the data indicates no significant microwave effect. Error bars represent maximum error.

$1000 / \mathrm{T}(\mathrm{K})$

The conductive palladium did not couple effectively with the microwave energy with respect to the alumina support. Had the metal coupled more strongly, the local metal surface temperature would be greater than the support, and the rate would appear faster in the microwave than the conventional furnace. The specific metal temperature was not observable for reasons described above.

The other possible effect considers a specific microwave effect on the desorption rate of $\mathrm{CO}$, the most likely area for a specific microwave effect. A specific effect would appear as a change in $\mathrm{CO}$ reaction order. Figure 6 shows the rate dependence as a function 
of $\mathrm{CO}$ partial pressure, yielding reaction orders (slopes) which are nearly identical. These results support the conclusion that the process is unaffected by the heating mode.

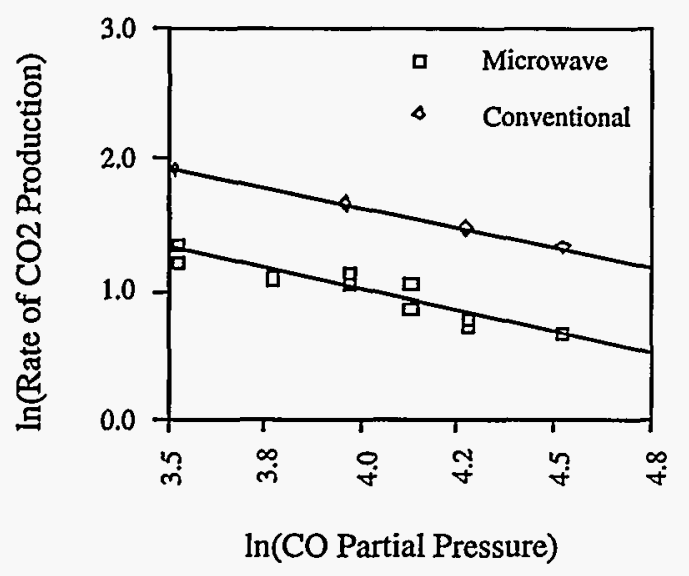

Figure 6. Plot indicates the dependence of the overall rate of reaction on $\mathrm{CO}$ partial pressure in both the microwave and conventional reactors. The slopes are -0.59 and -0.64 , respectively. The near equality of the slopes indicates that no significant alterations of the reaction pathway occurs in the microwave reactor. The conventional temperature was $135 \mathrm{C}$; the microwave temperature was not measured. Pressure is in Torr.

\section{Conclusion}

The primary conclusion obtained from the data presented is that no alterations in the kinetic behavior of the reaction were observed using the $\mathrm{Pd} / \mathrm{Al}_{2} \mathrm{O}_{3}$ catalyst. This was a significant result considering the potential for direct interaction of microwave energy with both the small Pd catalyst particles and the highly polar CO reactant.

We would like to stress the overriding theme of this research: The highly nonisothermal nature of the microwave heated packed bed can lead to improper conclusions about rate behavior. Taken at face value, early experimental results would have pointed to a significant rate enhancement which was clearly erroneous. Therefore, to correctly observe true chemical kinetics, the unique heat transfer effects that are present in a microwave heated experimental reactor must be carefully considered.

\section{Bibliography}

1. C-Y. Cha in Proceedings: Microwave-Induced Reactions Workshop, edited by $M$. Burka, R. D. Weaver, J. Higgins, (Electric Power Research Institute, Palo Alto CA, April 1993), p. A-2.

2. J. K. S. Wan and T. A. Koch in Proceedings: Microwave-Induced Reactions

Workshop, edited by M. Burka, R. D. Weaver, J. Higgins, (Electric Power Research Institute, Palo Alto CA, April 1993), p. A-3.

3. C. Chen, P. Hong, S. Dai, and J. Kan, J. Chem. Soc. Faraday Trans., 91(7), p. 1179. (1995)

4. M. S. Ioffe, S. D. Pollington, J. K. S. Wan, Journal of Catalysis, 151, p. 349 (1995).

5. H. S. Fogler, Elements of Chemical Reactor Engineering, 2nd Edition Prentice Hall, New Jersey, 1992, p. 217.

6. N. W. Cant, P. C. Hicks and B. S. Lennon, J. Catal. 54, p. 372 (1978).

7. P. J. Berlowitz, C. H. F. Peden, and D. W. Goodman, J. Phys. Chem., 92, p. 5213 (1988). 